\title{
Study on Dynamic Characteristics of a Hydraulic Suspension
}

\author{
Yaqin Wang \\ Anhui Technical College Of Mechanical and Electrical \\ Engineering \\ of China,Wuhu 241006 \\ e-mail: jxxwyq@126.com \\ Bin Qian \\ Anhui Technical College Of Mechanical and Electrical \\ Engineering \\ of China,Wuhu 241006 \\ e-mail: ahjdqb@126.com
}

\author{
Gaofa Nie \\ School of Mechanical and Automotive Engineering, \\ Anhui Polytechnic University, \\ of China, Wuhu 241000 \\ e-mail:niegaofa@163.com \\ Shanshan Peng \\ School of Mechanical and Automotive Engineering, \\ Anhui Polytechnic University, \\ of China, Wuhu 241000 \\ e-mail: $1285096601 @ q q o m$
}

\begin{abstract}
The dynamic characteristic test of the decoupling disc hydraulic mount designed by ourselves was performed firstly to establish surely the accurate simulation model of the hydraulic engine mount. In order to study the particular dynamic characteristic of the homemade decoupling disc hydraulic suspension, the test was measured under different working conditions. The test revealed the working mechanism of the hydraulic mount, and provided the design basis of the hydraulic mount structure and the theory of engine mount optimization. The experiment showed that under the same frequency, the dynamic stiffness increased with the load increasing, the lag angle, however, decreased with the increase of pre-load. Meanwhile the results also showed that as a whole, the dynamic stiffness and the hysteresis angle decreased with the increasing amplitude, but on the whole frequency band, its nonlinear characteristics of the dynamic stiffness changed evidently with the excitation amplitude.
\end{abstract}

Keywords: dynamic characteristics; decoupling; hydraulic suspension; stiffness; lag angle; frequency

\section{INTRODUCTION}

The hydraulic mount generally applied is a vibration-isolating device that was parallel connected by rubber bearing and the hydraulic system. The type of the hydraulic suspension structure is multiple, but they basic principle are the same. The decoupling hydraulic disc suspension is widely used because of its relatively simple structure, low manufacturing cost, and the excellent properties of its vibration isolation which can well meet the requirements of automotive vibration. The dynamic characteristic of decoupling disc hydraulic mount, however, is very complicated, so it is important to establish its simulation model. [1][2]

\section{CONSTRUCTION OF SYSTEM}

The test equipments use MTS850 test bench, as shown in Fig .1. The excitation device of MTS850 adopts numerical hydraulic servo vibration control system, mainly including the force sensors, the displacement sensor, the computer, the controller, the servo valve, the pump, the vibration head, and the charge amplifier, the $\mathrm{A} / \mathrm{D}$ and $\mathrm{D} / \mathrm{A}$ conversion module. The vibration head of the test bed can produce many excitation signals, such as triangle wave, sine wave, half sine wave, sawtooth wave and rectangular random wave etc, and can achieve the accurate control of force and displacement. The principle of the test system structure is shown in Fig .2. Homemade test samples of the decoupling disc hydraulic suspension are shown in Fig . 3. [3]
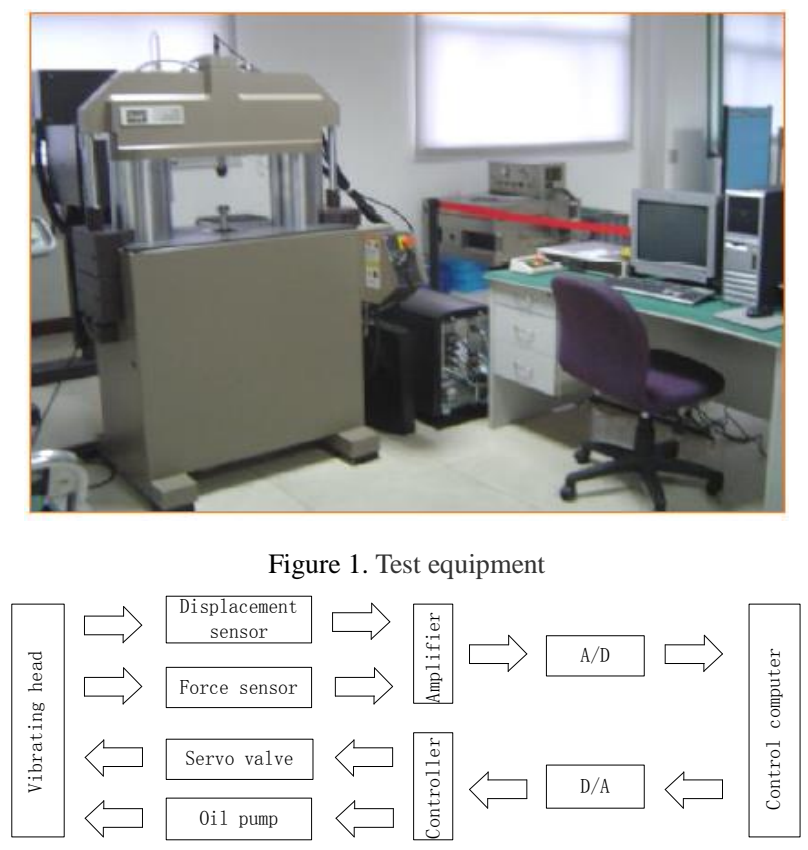

Figure 2. The test system structure principle block diagram 


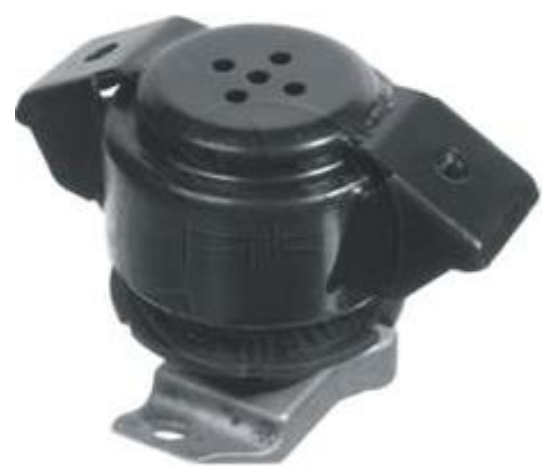

Figure 3. Test sample

\section{CHARACTERISTIC TEST OF HYDRAULIC} MOUNT

The evaluation index of hydraulic mount ought to consider two kinds of typical mechanical properties in the static and dynamic. When evaluates the dynamic characteristics of the hydraulic mount in engineering, the most common indicator is the dynamic stiffness and the hysteresis angle. The paper regarded the homemade test samples as the research object, discussing the influence of the pre-load, the vibration amplitude and the vibration frequency to its dynamic characteristics.

\section{A . Test of hydraulic mount static characteristic}

Suspension components were tested the static stiffness on the MTS test bench. The test controlled by a computer program could collect real-time data and draw curves. The biggest test force is $4 \mathrm{KN}$. The resolution displacement is higher than $0.1 \mathrm{~mm}$. The speed is step-less adjustable from 0.05 to $50 \mathrm{~mm} / \mathrm{min}$. After mount components were fixed on the MTS test bench, the vibration head of the test rig should be adjusted to ensure the centre axis of the suspended load and suspension. During the slow process of the test bench loading and unloading, the measured object change of force and displacement curves could be recorded, then the equivalent static stiffness in the tested direction could be calculated according to the relation of force and displacement (on the elastic segment).

Fig .4 is the static force - displacement curve of the hydraulic mount in $\mathrm{z}$-direction. And the least-square method was used to treat the test data of linear region [-10 $\mathrm{mm}, 15 \mathrm{~mm}$ ] for linear fitting, then static stiffness of the hydraulic mount could be measured $126.1 \mathrm{~N} / \mathrm{mm}$. Under the effect of static load, the main rubber spring bear almost the whole load, so the pressure of hydraulic suspension in quasi static tension, its static stiffness is equal to the static stiffness of rubber main spring.

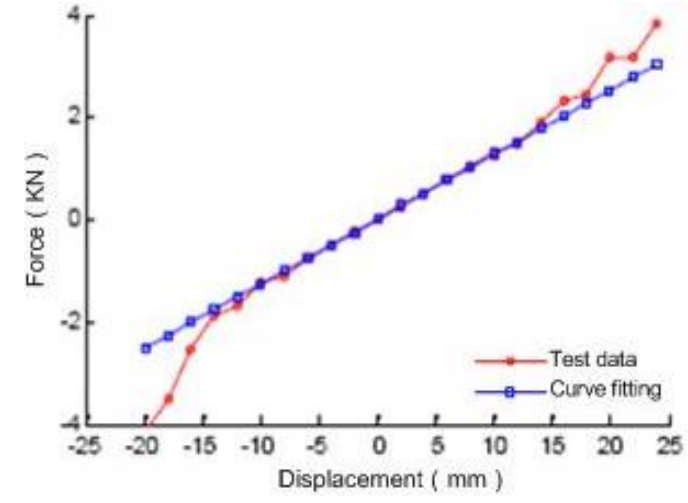

Figure 4. Test results for static stiffness in the $\mathrm{Z}$ direction of hydraulic engine mount

\section{B . Test of hydraulic mount dynamic characteristic}

When the experiment was performed, suspension components were, firstly, mounted on a certain load that was equal to the static load of power assembly, then the sine displacement excitation $\mathrm{x}(\mathrm{t})=\mathrm{X} \sin (\omega \mathrm{t})$ was exerted on the joint between the suspension and connection plate, where $\mathrm{x}$ is the excitation amplitude and $\omega$ is the vibration frequency. The displacement of the displacement sensor signal $x(t)$ and the force of the force sensor signal $F(t)$ ought to be recorded. The recorded data got though the Fourier transform, and then used the corresponding formula to calculate the dynamic stiffness and hysteresis Angle of hydraulic mount. The dynamic characteristic test of hydraulic mount mainly includes the low frequency and the large amplitude incentives and the high frequency and the small amplitude incentives, specific experimental parameters such as table 1 .

TABLE 1 .PARAMETERS OF THE DYNAMIC CHARACTERRISTICS OF HYDRAULIC ENGINE MOUNT

\begin{tabular}{|c|c|c|c|}
\hline Excitation type & Amplitude & Pre-load & $\begin{array}{c}\text { Test frequency } \\
\text { range }\end{array}$ \\
\hline \multirow{2}{*}{$\begin{array}{l}\text { Low frequency } \\
\text { Large amplitude }\end{array}$} & $0.75 \mathrm{~mm}$ & $\begin{array}{c}800 \mathrm{~N} \\
1000 \mathrm{~N} \\
1200 \mathrm{~N}\end{array}$ & $5 \sim 50 \mathrm{~Hz}$ \\
\hline & $1.00 \mathrm{~mm}$ & $\begin{array}{c}800 \mathrm{~N} \\
1000 \mathrm{~N} \\
1200 \mathrm{~N}\end{array}$ & $5 \sim 50 \mathrm{~Hz}$ \\
\hline \multirow{2}{*}{$\begin{array}{l}\text { High frequency } \\
\text { Small amplitude }\end{array}$} & $0.25 \mathrm{~mm}$ & $\begin{array}{c}800 \mathrm{~N} \\
1000 \mathrm{~N} \\
1200 \mathrm{~N}\end{array}$ & $10 \sim 200 \mathrm{~Hz}$ \\
\hline & $0.50 \mathrm{~mm}$ & $\begin{array}{l}800 \mathrm{~N} \\
1000 \mathrm{~N} \\
1200 \mathrm{~N}\end{array}$ & $10 \sim 200 \mathrm{~Hz}$ \\
\hline
\end{tabular}


When excitation amplitude was $0.75 \mathrm{~mm}$ and $1 \mathrm{~mm}$, the low-frequency dynamic stiffness and hysteresis angle of the hydraulic mount under different pre-load $(800 \mathrm{~N}$, $1000 \mathrm{~N}$ and $1200 \mathrm{~N}$ ) were shown in Fig .5and Fig . 6. The figure showed that the dynamic stiffness increased with the increase of the frequency and peaked in $23 \mathrm{~Hz}$. Then it decreased with the increase of frequency. The lag angle increased with the increase of frequency and peaked at 14 $\mathrm{Hz}$. Then it decreased with the increase of frequency, finally tending to a constant value. Under the same frequency, the dynamic stiffness increased with the load increasing, the lag angle, however, decreased with the increase of pre-load.

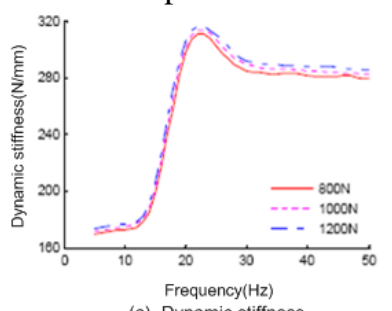

(a) Dynamic stiffness

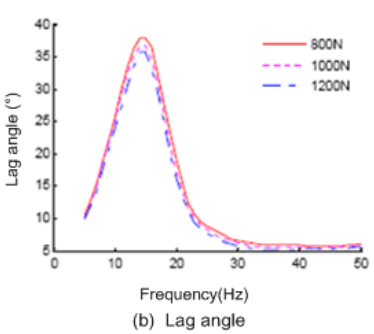

(b) Lag angle
Figure 5. Low-frequency performance for HEM under different preload

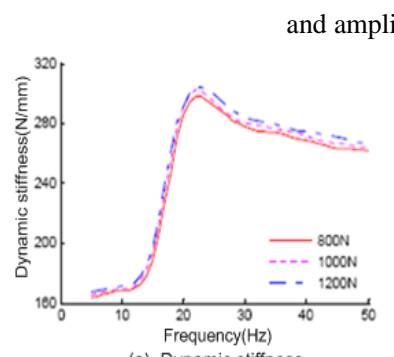

(a) Dynamic stiffness

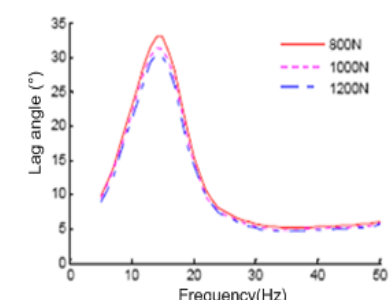

(b) Lag angle
Figure 6. Low-frequency performance for HEM under different preload and amplitude $1 \mathrm{~mm}$

When excitation amplitude was $0.25 \mathrm{~mm}$ and $0.5 \mathrm{~mm}$, the high-frequency dynamic stiffness and the hysteresis angle of the hydraulic mount under different pre-load $(800 \mathrm{~N}, 1000 \mathrm{~N}$ and $1200 \mathrm{~N})$ were shown in Fig .7 and Fig .8. The figure showed that the dynamic stiffness did not change significantly within $35 \mathrm{~Hz}$, but after that as the frequency increased, the dynamic stiffness increased with the changeable growth rate, and peaked near $170 \mathrm{~Hz}$, and then decreased with the increasing frequency. The lag angle increased with the increase of frequency and peaked at $70 \mathrm{~Hz}$ and then it decreased with the increase of frequency. Under the same frequency, the dynamic stiffness increased with load increasing, the lag angle, however, decreased with the increase of pre-load.
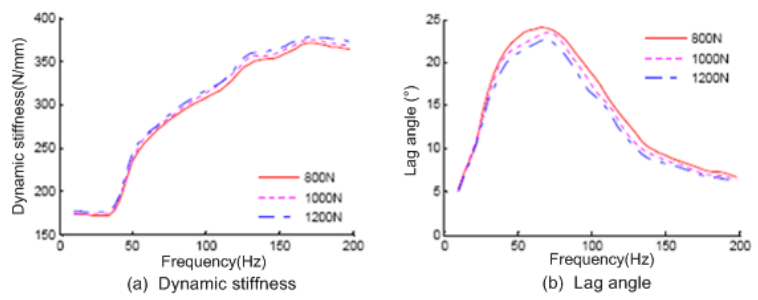

Figure 7. High-frequency performance for HEM under different preload and amplitude $0.25 \mathrm{~mm}$
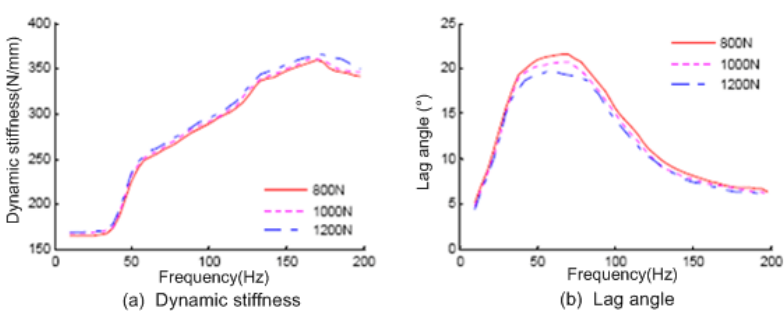

Figure 8. High-frequency performance for HEM under different preload

$$
\text { and amplitude } 0.5 \mathrm{~mm}
$$

The dynamic characteristics of the hydraulic mount in the low frequency and the high frequency under different amplitude were respectively shown in Fig .9 and Fig .10. The figure showed that the dynamic stiffness and the hysteresis angle, as a whole, decreased with the increasing amplitude, but on the whole frequency band, its change was very complicated. Thus the nonlinear characteristics of the dynamic stiffness changed evidently with the excitation amplitude. The structure and the layout of the internal flow of hydraulic mount influenced its dynamic stiffness characteristic, making it show obvious nonlinear characteristics.
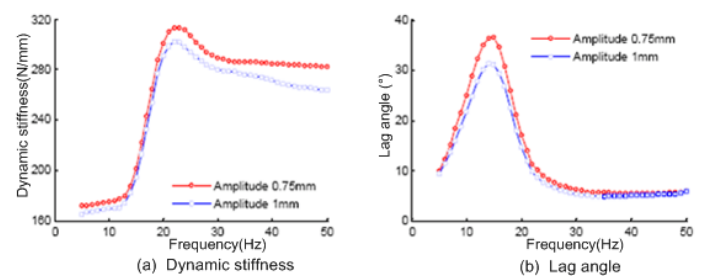

Figure 9. Low-frequency performance for HEM under different excitation amplitude
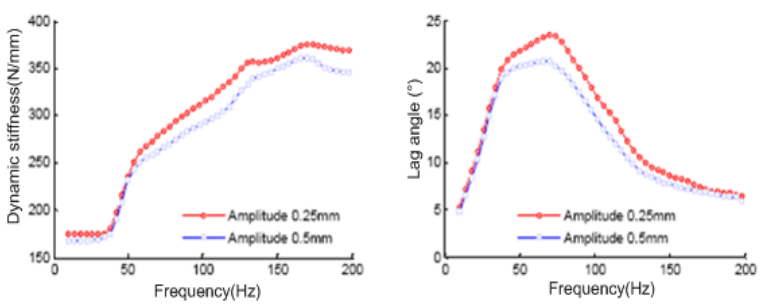

(a) Dynamic stiffness

(b) Lag angle

Figure 10. High-frequency performance for HEM under different

excitation amplitude

\section{CONCLUSION}

The dynamic characteristic test of the homemade decoupling disc hydraulic suspension was performed on two typical working condition, obtaining the dynamic characteristics of hydraulic mount under different working conditions, and providing theoretical reference to reveal the working mechanism of hydraulic mount and the structure design.

\section{ACKNOWLEDGEMENTS}

The authors would like to thank the financial supports of Anhui Provincial Natural Science Foundation (Grant No. 1508085ME70) and teacher 
studio, 2014 colleges and universities in Anhui province quality project, (Grant No. 2014 msgzs 189), project leader: Yaqin Wang.

\section{REFERENCES}

[1] J. F. Hu, R. Singh. Improved torque roll axis decoupling axiom for a powertrain mounting system in the presence of a compliant base [J]. Journal of Sound And Vibration, 2012,331 (7): 1498-1518.

[2] Qin Min, Lin Yi, Ma Tieli. Dynamic characteristic research of automobile hydraulic suspension system[J]. Automotive Engineering. 2011,33(6):381-384. (in Chinese)

[3] Yang Wei, Shi Wenku, Ma Lihong, Pan Bin, Xu Bo. An Experimental Study on the Hydraulic Mount Parameters of Automotive Powertrain[J]. Automotive Engineering, 2014, 36(7):894-898. (in Chinese)

[4] Li Qian. Study on the Dynamic Characteristic and Parameter Identification of Hydraulic Engine Mount in Automotive Powertrain Mounting System [D].Shanghai: Shanghai Jiao Tong University, 2010. (in Chinese)
[5] Shu Changdong. Study on the Dynamic Characteristics and A Simulation of Hydraulic Engine Mount in Automotive Engine Mounting System [D].Shanghai: Donghua University, 2012. (in Chinese)

[6] Truong T Q, Ahn K K. A new type of semi-active hydraulic engine mount using controllable area of inertia track $[\mathrm{J}]$.

Journal of Sound and Vibration,2010,329(1):247-260.

[7] Sun Linfeng, Fan Wenxin. Research of development of the engine mount[J]. Internal Combustion Engines,2010,6(3):19-22. (in Chinese)

[8] Jae-Yeol Park, Rajendra Singh. Role of spectrally varying mount properties in influencing coupling between powertrain motions under torque excitation[J].Journal of Sound and Vibration,2010,329(14): 2895-2914.

[9] Shi Peicheng, Chen Wuwei, Jiang Wuhua. Simulation Research on Hydraulic Mount Nonlinear Dynamic Characteristics [J] Chinese Mechanical Engineering, 2009, 24(2):2545-2548. (In Chinese)

[10] Li Qian. Study on the Dynamic Characteristic and Parameter Identification of Hydraulic Engine Mount in Automotive Powertrain Mounting System [D].Shanghai: Shanghai Jiao Tong University, 2010. (In Chinese) 